\title{
Granuloma Esquistossomótico Gigante do Cólon com Intussuscepção: Relato de Caso
}

\section{Giant Schistosomal Granuloma of the Colon with Intussusception: Case Report}

\author{
RODRIGOBRITTODECARVALHO ${ }^{1}$,HERNÁNAUGUSTOCENTURIÓN SOBRAL ${ }^{2}$, \\ JULIANA MAGALHÃES LOPES ${ }^{1}$, LILIAM RAMOS TODINOV ${ }^{2}$, GALDINO JOSÉ SITONIO FORMIGA ${ }^{3}$
}

1 Médicos residentes do Serviço de Coloproctologia do Hospital Heliopólis; 2 Médicos Assistentes do Serviço de Coloproctologia do Hospital Heliopólis; 3 Chefe do Serviço de Coloproctologia do Hospital Heliopólis.

\begin{abstract}
CARVALHO RB; SOBRAL HAC; LOPES JM; TODINOV LR; FORMIGA GJS. Granuloma Esquistossomótico Gigante do Cólon com Intussuscepção: Relato de Caso. Rev bras Coloproct, 2008;28(3): 347-349.

RESUMO: A esquitossomose é uma doença parasitária crônica causada por uma espécie de trematódeo, o shistossoma, acometendo 200 milhões de pessosas em todo mundo. No Brasil é provocada pela espécie Shistossoma mansoni, cuja apresentação clínica mais comum é a hepato-intestinal, com sintomas como diarréia, tenesmo, náuseas, meteorismo e hepato-esplenomegalia. Relatamos um caso de paciente masculino de 38 anos com quadro de exteriorização de tumor pelo ânus. A colonoscopia demonstou lesão nodular extra-mucosa em topografia de sigmóide. Submetido a sigmoidectomia, cujo anátomo-patológico mostrou tratar-se de granuloma esquistossomótico gigante, apresentação muito rara da esquistossomose.
\end{abstract}

Descritores: Esquistossomose, pólipo, intussuscepção, sigmóide, granuloma.

\section{INTRODUÇÃO}

A esquistossomose ou bilharziose é uma doença infecciosa granulomatosa causada por helmintos do gênero Shistossoma, sendo o S. mansoni o agente responsável no Brasil. A primeira citação da doença foi feita por Teodor Bilharz em1851 ${ }^{1}$. É uma afecção de grande prevalência, acometendo aproximadamente 200 milhões de pessoas em todo mundo, com outros 400 milhões com risco de serem infectados ${ }^{2}$.

O objetivo deste trabalho é relatar um caso raro de pólipo esquistossomótico gigante de sigmóide com intussuscepção e exteriorização anal, não sendo encontrado outro relato semelhante na literatura consultada.

\section{RELATO DO CASO}

Paciente masculino, 38 anos, natural de Pernambuco, há três meses com prolapso de tumor anal aos esforços, hematoquezia, puxo e tenesmo. Exame parasitológico de fezes negativo. A colonoscopia evidenciou lesão polipóide extramucosa de $5 \mathrm{~cm}$ de diâmetro em sigmóide, que foi biopsiada e o exame histopatológico revelou processo inflamatório inespecífico. CT de abdome demonstrou lesão nodular endo-luminal com densidade de gordura e imagem em casca de cebola sugestiva de intussuscepção (Figura 1).

Devido à impossibilidade de ressecção endoscópica, o paciente foi submetido a sigmoidectomia (Figura 2), cujo anatomopatológico evidenciou granuloma piogênico com ovos de Shistossoma mansoni (Figuras 3, 4 e 5). Evoluiu no sétimo pós-operatório com quadro de abdome agudo obstrutivo, sendo submetido a laparotomia exploradora que demonstrou hérnia interna de íleo terminal sem sofrimento vascular, que foi prontamente corrigida.

$\overline{\text { Trabalho realiza }}$ do no Serviço de Coloproctologia do Hospital Heliópolis - São Paulo - Brasil. 


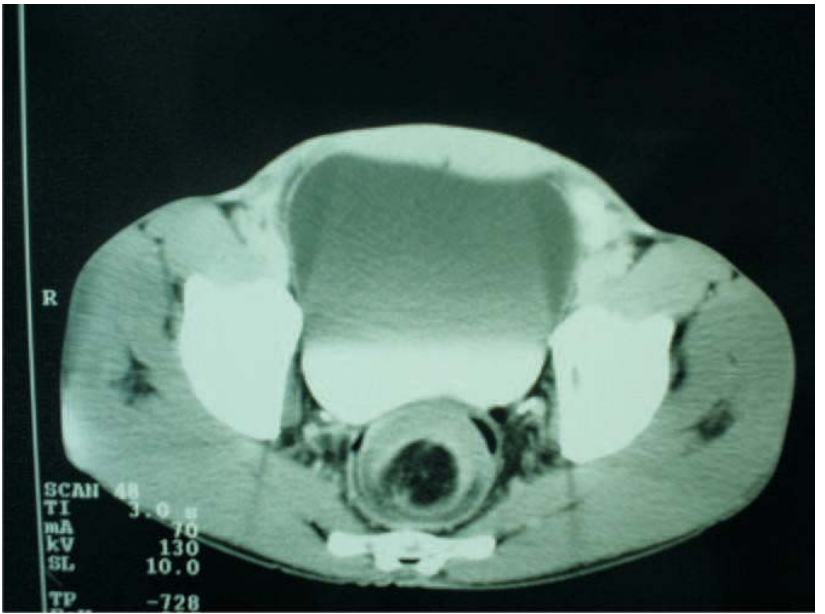

Figura 1-CT de pelve com imagem nodular hipodensa na luz do reto.

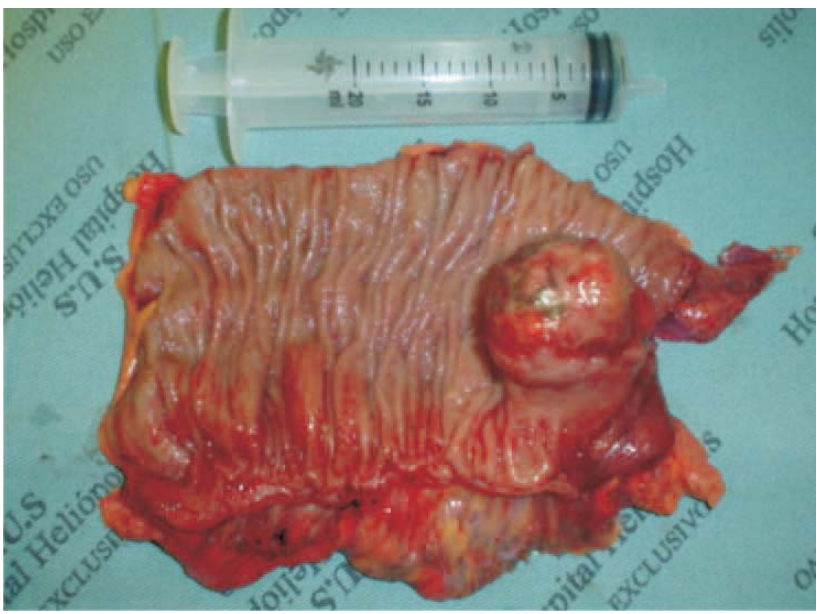

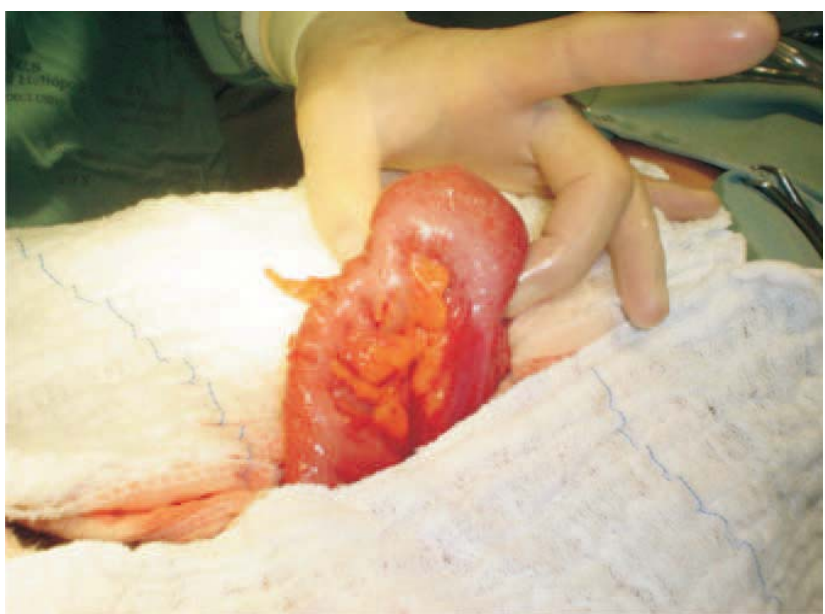

Figura 2 - Aspecto da lesão no intra-operatório.

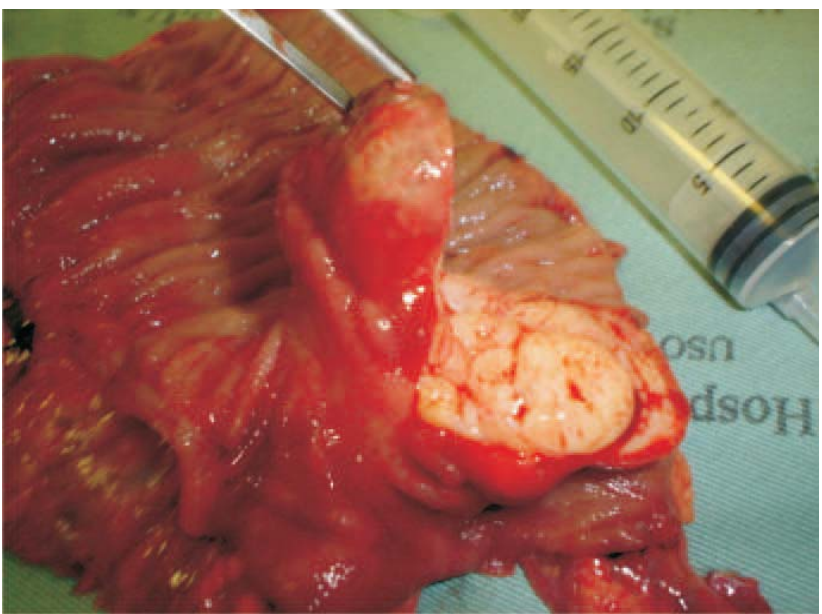

Figuras 3 e 4 - Aspecto macroscópico após abertura da peça e da lesão.

O paciente foi submetido a tratamento complementar com praziquantel $(40 \mathrm{mg} / \mathrm{kg})$, recebendo alta ambulatorial após seis meses de acompanhamento.

\section{DISCUSSÃO}

A esquistossomose acomete aproximadamente $8 \%$ da população brasileira, sendo endêmica em certas regiões como o Nordeste, onde atinge até $20 \%$ dos habitantes ${ }^{1}$.

Tem manifestação clínica variada, com duas fases evolutivas distintas: inicial ou aguda e crônica. A fase aguda conhecida como febre de Katayama, surge de um a dois meses após a infecção, com febre alta, mialgias, astenia, cefaléia e tosse seca. A fase crônica acomete principalmente o aparelho digestivo, com dispepsia, surtos diarréicos (em alguns casos

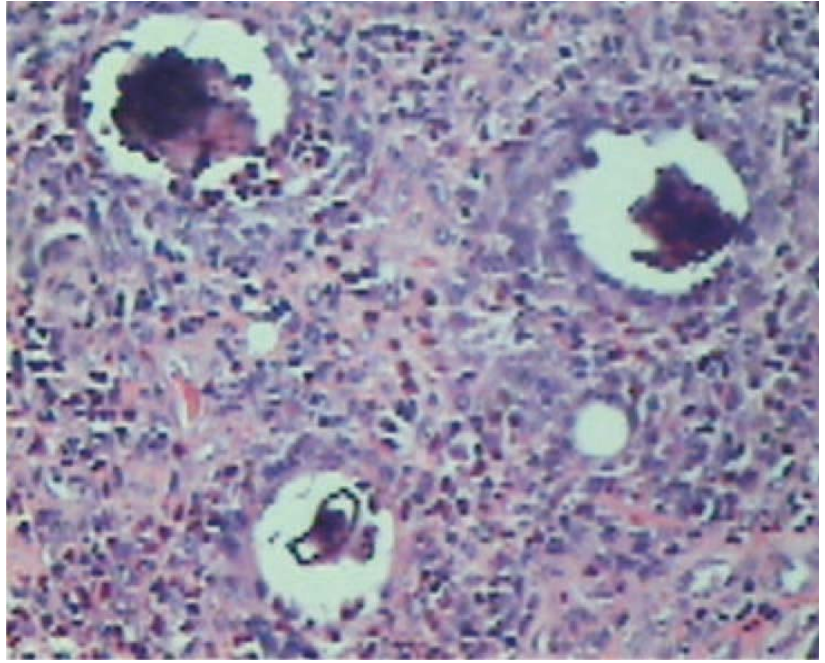

Figura 5 - Anatomopatológico: granuloma esquistossomótico (HE/ 100X). 
sanguinolentos), meteorismo, tenesmo, hepatoesplenomegalia, e por fim sinais de hipertensão por$\operatorname{tal}^{3}$.

O diagnóstico é baseado no quadro clínico e na epidemiologia, e confirmado por exames laboratoriais que demonstram ovos do parasito nas fezes ou em biópsias $^{1-5}$.

Exames endoscópicos como retossigmoidoscopia ou colonoscopia podem auxiliar no diagnóstico, evidenciando hiperemia, ulcerações, friabilidade da mucosa e pólipos inflamatórios. Sanguino et al descrevem alterações vasculares características: interrupção súbita do vaso rodeado por petéquias com aspecto de "mordida de pulga" ou anel'.

Histologicamente, caracteriza-se por granuloma não caseoso, com ovo do shistossoma central $^{7,8}$. Santana et al relataram um caso de granuloma esquistossomótico gigante mimetizando tumor de sigmóide com sintomas obstrutivos ${ }^{9}$. No nosso caso a esquistossomose manifestou-se como um tumor polipóide gigante com intussuscepção e exteriorização pelo ânus, fato não descrito na literatura consultada.

Intussuscepção é mais freqüentemente causada por tumores malignos, pólipos adenomatosos e lipomas, ocorrendo raramente em adultos. Pode ocorrer de forma oculta com sintomas inespecíficos como dor abdominal, náuseas e vômitos ou exteriorizar-se pelo ânus 10

O tratamento da esquistossomose é medicamentoso, com alta eficácia e baixa toxicidade. As drogas utilizadas são oxaminiquine $(15 \mathrm{mg} / \mathrm{kg})$, agindo nas formas adultas, impedindo a oviposição e praziquantel (40 mg/kg), sendo eficaz tanto na fase aguda como na crônica ${ }^{1-3}$.

Grande parte das intussuscepções é tratada cirurgicamente, pois geralmente se associam a neoplasia ${ }^{10}$, justificando a laparotomia com sigmoidectomia no nosso paciente, sendo o diagnóstico apenas dado pelo anatomopatológico.

Agradecimento especial ao Serviço de Anatomia-Patológica do Hospital Heliópolis

ABSTRACT: Shistosomiasis is a chronic parasitic illness caused by Shistossoma Mansoni, responsible for 200 million cases all over the world. The most common presentation is hepatic-intestinal form with symptoms as diarrhea, tenesmus, hepatomegaly, abdominal pain and nausea. We report a case of a male patient, 38 years with anal polyp prolapse, confirmed by colonoscopy, located in the sigmoid. The patient was submitted to sigmoidectomy, which through a histological study of the surgical specimen a giant shistosomal granuloma of the colon was evidenced. The aim of this report is to describe a rare and atypical manifestation of a case of shistosomosis.

Key words: Shistosomiasis, polyp, sigmoid, intussusception, granuloma.

\section{REFERENCIAS}

1. Motta LP, et al. Esquistossomose Mansoni-Estado Atual. JMB.1994; 66(3): 113-99.

2. Mutapi F, Mduluza T, et al. Immuno-epidemiology of human Shistosoma haematobiuminfection: preferential IgG3 antibody responsiviness to a recombinant antigen dependent on age and parasite burden. BMC Infectious Diseases. 2006; 6:96

3. Vidal MAN, Torres Neto JR, Santana NMB, Salviano SKM, Déda RG. Esquistossomose Retal - Aspectos Clínicos e Endoscópicos. Rev bras Coloproct. 2001; 21(2): 70-71.

4. Reis RJN, Ferreira AL, Ferreira JJ, Salazar HC. Esquistossomose mansoni: Diagnóstico pela biópsia retal e parasitológico em 100 casos selecionados. Rev bras Coloproct. 1984;4(2):99-101.

5. Rabello ALT et al. Dot-DYE-Imunoassay for the diagnosis of shistosomiasis mansoni. Mem Int Oswaldo Cruz. 1992; 87(2):187-190.
6. Sanguino J, Peixe R et al. Shistosomiasis and vascular alterations of colonic mucosa. Hepato-Gastroenterol. 1993;40:184-187.

7. Robbins $\mathrm{P}$ et al. Patologia functional. Ed. Guanabara-Koogan. Riode Janeiro.1998: 1047

8. Silva LM et al. Significance of Shistosomal Granuloma Modulation. Mem Int Oswaldo Cruz.2000;95(3):352-361.

9. Santana HJ, Lima CA. Pseudotumor esquistossomótico de cólon - relato de um caso. Rev bras Coloproct.1985; 5(1):17-21.

10. Ki-Jae P, Hong-Jo C, Sung-Heun K. Sigmoidorectal intussusception of adenoma of sigmoid colon treated by laparoscopic anterior resection after sponge-on-the-stick-assisted manual reduction. World J Gastroenterol. 2006;12(1):146-149.

Endereço para correspondência:

GALDINO JOSÉ SITONIO FORMIGA

Hospital Heliópolis - Serviço de Coloproctologia

Rua Cônego Xavier, 276 - Vila Heliópolis

04231-030 - São Paulo-SP

Tel: (11) 2274-7600 (Ramal 244) 